\title{
Radiolabeling Technique of Silver Nanoparticles (AgNPs) with lodine-131 Radionuclide
}

\author{
U.N. Sholikhah ${ }^{1 *}$, R.R. Syahdi ${ }^{2}$, S.E. Permatasari ${ }^{2}$, E. Sarmini ${ }^{1}$, Sriyono $^{1}$ and \\ T. Widyaningrum ${ }^{1}$ \\ ${ }^{1}$ Center for Radioisotopes and Radiopharmaceutical Technology, National Nuclear Energy Agency (BATAN), \\ Puspiptek Area Serpong, Tangerang Selatan 15314, Indonesia \\ ${ }^{2}$ Department of Pharmacy, University of Indonesia, Jl. Margonda Raya, Depok 16424, Indonesia
}

\section{ARTICLE INFO}

Article history:

Received 11 October 2017

Received in revised form 27 March 2020

Accepted 28 March 2020

Keywords:

Gamma counter

Radiochemical purity

Radionuclide purity

Radiotheraphy

\begin{abstract}
A B S T R A C T
Radiotherapy is an effective cancer therapy, where a certain dose of radiation is aimed specifically at target and is unaffecting to normal tissue. A selective radionuclide must be attached to the specific targeted organ. In this research, silver nanoparticles (AgNPs) were labeled with radionuclide of iodine-131 $\left({ }^{131} \mathrm{I}\right)$ to be used in radiotherapy. Silver nanoparticles were synthesized using silver nitrate $0.0005 \mathrm{M}$, sodium borohydride $0.002 \mathrm{M}$, polyvinylpyrrolidone $0.3 \%(\mathrm{w} / \mathrm{v})$ and natrium chloride $1.5 \mathrm{M}$, and then followed by purification by centrifugation. Characterization was carried out with UV-Vis spectrophotometer, transmission electron microscope, particle size analyzer, and zeta-sizer. The results show that the maximum absorbance is on a wavelength of $398 \mathrm{~nm}$, spherical shape with a diameter of $10 \mathrm{~nm}$, polydispersity index of 0.455 , and zeta potential value of $-8 \mathrm{mV}$. The radiolabeling was done by adding sodium iodide- 131 which had been oxidized by chloramine-T and immobilized in AgNPs colloidal solution, and the activity was then measured using a dose calibrator. The identification of radionuclide showed that the sample was free of impurities. The optimum system of radiochemical purity was obtained using Whatman 1 paper strip as the stationary phase and a mixture of methanol: water: ammonium acetate (1:1:1) as the mobile phase, which gave $96 \%$ purity. This method is suitable for radiolabeling AgNPs with ${ }^{131}$ I to be used for radiotherapy.
\end{abstract}

(C) 2020 Atom Indonesia. All rights reserved

\section{INTRODUCTION}

Radiopharmaceuticals are biologically active compounds labeled with radionuclide, which are designed for diagnostics or therapy in certain cells [1]. Its purpose is directing the radionuclide to the treated target as therapy or obtain an image as diagnostic [2,3]. The application of radiopharmaceuticals plays an important role in nuclear medicine and molecular imaging [4] because the diagnosis can be accomplished with more accurate result and easier. Ideal radiopharmaceuticals for targeted therapy are specific to the targeted organ, stable in high dose and simple administration methods [5].

Nanomedicine seems to be promising to overcome malignancy. Nanomedicine applications

\footnotetext{
*Corresponding author.

E-mail address: uminurs@batan.go.id

DOI: https://doi.org/10.17146/aij.2020.745
}

depend on the morphologies, and each morphology has different properties. Silver nanoparticles (AgNPs), for instance, have some morphologies, such as cubic, bar, rod, triangular, prism, tubes, cylinders, and spheres [6]. Furthermore, nanodimensional structures are capable of carrying and transmitting radionuclides. Nanoparticle investigations should inform the interaction of tissues and cells with nanoparticles. Drug delivery system of nanomedicine has been used in clinics as a carrier for sensitive chemotherapy, and the radiolabeled nanoparticle is a novel class of radiopharmaceutical agents with great potential in some clinical applications because of its stability in plasma and high sensitivity in imaging (it becomes a promising radioimaging agent) [7]. The success of cancer treatments and imaging depends on the unique characteristic of the nanomedicine. The enhanced permeation and retention (EPR) effect in tumors cell is one of the 
characteristics of nanoparticles due to their very small size and surface properties, thus giving the effect of penetration and retention that allows increasing localization [8].

In previous research by Charastina et. al., labeling using Iodine-125 $\left({ }^{125} \mathrm{I}\right)$ has been reported [9]. This isotope is used for in-vitro assays and developed for in-vivo as imaging radiopharmaceutical. Radioisotopes other than iodine-131 $\left({ }^{131} \mathrm{I}\right)$ that have similar chemical properties can be used for radiolabeling of AgNPs. As generally known, specific emission characteristics of radionuclide Iodine-131 $\left({ }^{131} \mathrm{I}\right)$ is suitable for radiotherapy and Single-Photon Emission Computed Tomography (SPECT) imaging. Therefore, radiolabeling using Iodine isotopes can be developed for radiotherapy and imaging. The radionuclide ${ }^{131} \mathrm{I}$ and ${ }^{125} \mathrm{I}$ have been widely used for tumor radiotherapy so that intracavitary targeting or intracavitary brachytherapy of ${ }^{125} \mathrm{I}$ or ${ }^{131} \mathrm{I}$ labeled nanoparticles can be used as nanocarriers for irradiation, especially for liver cancer treatment. Radiopharmaceutical products must fulfill 2 main components of radiation characteristics and chemical compounds (with their structural or chemical properties). Both components determine the in-vivo distribution and physiological properties, so identification of radionuclide impurities is important because it can affect the accuracy of imaging and therapy, and these impurities will be accumulated in the organ during the blood circulation time [10].

Many researches have focused on nanoparticle synthesis. However, the radiolabeling techniques of nanoparticle are still limited especially to AgNPs. Based on the previously discussed stable AgNPs, we modified the scale-up process of its synthesis and purification. The AgNhave great potential in breast cancer therapeutic [11]. This article presents the labeling method of AgNPs using radionuclide ${ }^{131} \mathrm{I}$. The development of radiolabeled nanoparticles has great potential in diagnosing cancer by producing accurate and precise assessments of cancer in real-time so that cancer pathways can be identified. This research aimed to study the ${ }^{131}$ I radiolabeling technique to AgNPs by chloramine- $T$ Iodination. Some characterizations were done using UV-Vis spectrophotometer, transmission electron microscope (TEM), particle size analyzer (PSA), zeta-sizer, gamma counter, and gamma-ray spectrometer. Radiochemical and radionuclide purity of the results are also calculated.

\section{EXPERIMENTAL METHODS}

The materials used were silver nitrate $\left(\mathrm{AgNO}_{3}\right)$, sodium chloride $(\mathrm{NaCl})$, phosphate buffer
pH 7, methanol $\left(\mathrm{CH}_{3} \mathrm{OH}\right)$, ammonia $\left(\mathrm{NH}_{3}\right)$, glacial acetic acid $\left(\mathrm{CH}_{3} \mathrm{COOH}\right)$ and universal $\mathrm{pH}$ indicator, which were purchased from Merck. Other materials used such as sodium borohydride $\left(\mathrm{NaBH}_{4}\right)$, polyvinylpyrrolidone-360 (PVP-360), chloramine-T, Whatman No.1 filter paper were purchased from Sigma Aldrich. The sodium iodide-131 used in this research was produced from the Center for Radioisotope and Radiopharmaceuticals, BATAN. The glass beads used were purchased from a local company while the sterile aquabidest was purchased from IPHA.

The instruments used in this research were UV-Vis spectrophotometer (Lambda 45, Perkin Elmer), centrifugator (1730R, Labogene), gamma counter (Gammatec II Nucleus 600B), dose calibrator (AtomLab 100), gamma spectrometer (Canberra), particle size analyzer (PSA) and zeta-sizer (Malvern, BB Pascapanen Laboratory), transmission electron microscope (FEI Tecnai G2 20 S-Twin, LIPI), and analytical balances (AccuLab). The tools used were chromatography vessel, micropipet (Eppendorf), syringe (Terumo) and a set of glassware.

Radiolabeling of AgNPs with ${ }^{131}$ I was carried out in 3 steps: a) scaled-up synthesis of AgNPs and purification, b) radiolabeling of AgNPs using ${ }^{131} \mathrm{I}$ and c) quality control of AgNPs $-{ }^{131}$ I product.

\section{Scaled-up synthesis of AgNPs and purification}

The synthesis method of AgNPs referred to Sholikhah et. al. [12] with some modification. The synthesis was scaled up with multi-steps of the purification step. It was done by reacting $5 \mathrm{~mL}$ $\mathrm{AgNO}_{3} 0.0005 \mathrm{~N}$, reducing by $5 \mathrm{~mL} \mathrm{NaBH}_{4} 0.002 \mathrm{~N}$ and then stabilizing using $200 \mu \mathrm{L}$ PVP $0.3 \%$ (w/v) and $100 \mu \mathrm{L} \mathrm{NaCl} 1.5 \mathrm{~N}$. The mole ratio of the reducing agent $\left(\mathrm{NaBH}_{4}\right)$ and starting material $\left(\mathrm{AgNO}_{3}\right)$ is 4:1. Purification of AgNPs was done by centrifugation at $12,210 \mathrm{rpm}$ for 30 minutes at $4{ }^{\circ} \mathrm{C}$. The pellet was then resuspended with $400 \mu \mathrm{L}$ phosphate buffer $\mathrm{pH} \mathrm{7,} \mathrm{followed} \mathrm{by} \mathrm{centrifugation} \mathrm{at}$ $8000 \mathrm{rpm}$ for 15 minutes at $4{ }^{\circ} \mathrm{C}$ [13]. The produced AgNPs were analyzed using UV-Vis spectrophotometer for the determination of optical properties, TEM for particle size and morphology, PSA for particle size distribution, and zeta-sizer for zeta potential measurement.

\section{Measurement of radionuclide and radiochemical purity of ${ }^{131}$ I}

The radionuclide and radiochemical purity was determined by measurement of the $\mathrm{Na}^{-{ }^{131} \mathrm{I}}$ 
purity using a gamma-ray spectrometer. Each sample was adsorbed on a rounded Whatman No 1 filter paper and then placed at the spacer. The measurement of purity by gamma spectrometry is based on the energy detected.

\section{Radiolabeling of AgNPs with ${ }^{131}$ I}

Immobilization of chloramine- $\mathrm{T}$ on glass beads was done by immersing 1 gram glass bead in $5 \mathrm{~mL}$ of $0.0005 \mathrm{M}$ chloramine- $\mathrm{T}$ for $30 \mathrm{~min}$. The glass beads then were transferred into a clean vial. A solution of $\mathrm{Na}^{131} \mathrm{I}(500 \mu \mathrm{L})$ was measured for its radioactivity using dose calibrator and then it was added into a vial containing immobilized Chloramine-T glass beads; the mixture was allowed to react for 10 minutes. The solution of ${ }^{131} 1$ which has been oxidized was then transferred into a vial containing $1 \mathrm{~mL}$ of AgNPs, and the mixture was allowed to react for 30 minutes at room temperature. This step was completed without further purification. Radioactivity of $\mathrm{AgNPs}^{-131}{ }^{1} \mathrm{I}$ activity was then measured with a dose calibrator.

\section{AgNPs ${ }^{131}$ I quality control}

Quality control for the manufacturing product of $\mathrm{AgNP}^{131} \mathrm{I}$ is an important step to estimate radiochemical purity of the radiolabeled compound (AgNP- $\left.{ }^{131} \mathrm{I}\right)$ formed. The radiochemical purity was determined by thin-layer chromatography (TLC), where Whatman paper No. 1 strip $(1 \mathrm{~cm}$ x $17 \mathrm{~cm})$ was used as the stationary phase and a mixture of methanol:water: ammonium acetate $(1: 1: 1, \mathrm{v}: \mathrm{v}: \mathrm{v})$ as the mobile phase. A drop $(5 \mu \mathrm{L})$ of $\mathrm{AgNPs}^{131}{ }^{13} \mathrm{I}$ was spotted to Whatman paper No. 1 strip and then dried. The sequential processes in the chromatographic strip were development, drying, and measurement of its radioactivity distribution using a gamma counter. This procedure is also performed for $\mathrm{Na}^{-131} \mathrm{I}$ bulk as a standard in measuring the percentage of the free $\mathrm{Na}-{ }^{131} \mathrm{I}$ (or Na- ${ }^{131} \mathrm{I}$ that is not attached to AgNPs).

\section{RESULTS AND DISCUSSION}

In this research, the preparation of AgNPs has been performed by chemical reduction method with sodium borohydride as a strong reducing agent to produce well-controlled size of AgNPs. The mechanism of nanoparticle formation using sodium borohydride can be expressed as in Eq. (1) [14]:

$$
\mathrm{AgNO}_{3}+\mathrm{NaBH}_{4} \rightarrow \mathrm{Ag}+1 / 2 \mathrm{H}_{2}+1 / 2 \mathrm{~B}_{2} \mathrm{H}_{6}+\mathrm{NaNO}_{3}
$$

In AgNPs synthesis, PVP should be added first followed by the addition of $\mathrm{NaCl}$. The addition of PVP without $\mathrm{NaCl}$ may result in aggregation, so in this case PVP acts as a stabilizer. The addition of $\mathrm{NaBH}_{4}$ into an $\mathrm{AgNO}_{3}$ solution was aimed at reducing $\mathrm{Ag}^{+}$to become $\mathrm{Ag}^{0}$ followed by color change from colorless to yellow. This result conforms a result reported by Yena et. al. [15]. In this reaction $\mathrm{AgNO}_{3}$ is reduced by $\mathrm{NaBH}_{4}$. The mole ratio of reducing agent to $\mathrm{AgNO}_{3}$ has to be proportional. If the mole ratio of the reducing agent is insufficient, silver will not be reduced properly. This experiment used an excessive amount of $\mathrm{NaBH}_{4}$ as a reducing agent to ensure complete formation of AgNPs. The mole ratio in this study, $\mathrm{NaBH}_{4}: \mathrm{AgNO}_{3}=4: 1$, was found to be the best for the reduction processes, which resulted in AgNPs suitable to be radiolabeled with ${ }^{131} \mathrm{I}$. The AgNPs synthesis without the addition of $\mathrm{NaCl}$ will result in aggregation followed by precipitation when AgNPs re-suspends in the presence of phosphate buffer $\mathrm{pH} 7$.

The colloidal solution of AgNPs was found to give maximum absorption at the wavelength of about $397 \mathrm{~nm}$ on the $1^{\text {st }}$ day after purification. The UV-Vis spectrum was red-shifted after storage at $4{ }^{\circ} \mathrm{C}$ for 8 days after purification. This maximum absorption shifted to a longer wavelength of $398 \mathrm{~nm}$. Red-shift occurs due to interaction among particles and position shift of a peak to longer wavelength or lower energy (as a bathochromic shift). The peak position of the surface plasmon resonance (SPR) depends on many factors, such as particle size, dispersion medium, shape and surface chemistry of the particles [16-18].

Based on visual observation, the AgNPs was stable after storage for 7 days without color change and aggregation as shown in Fig. 1.

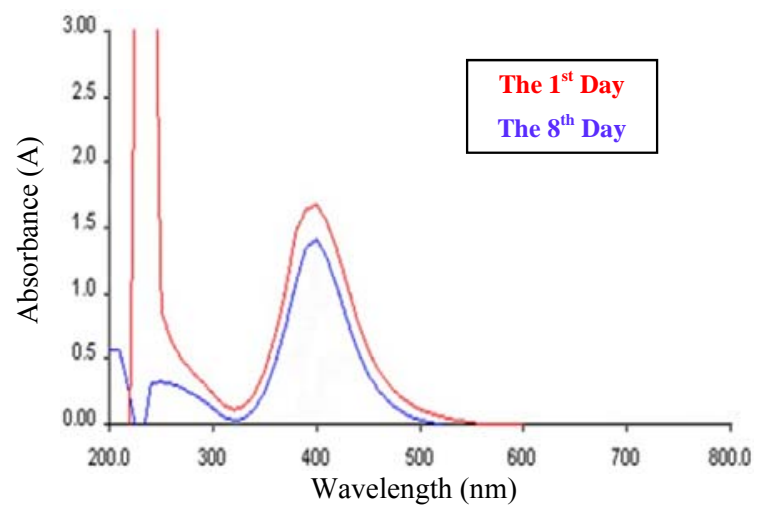

Fig. 1. UV-Vis Spectra of AgNPs.

This stability exceeds the half-life of radionuclide

${ }^{131} \mathrm{I}$, so it is suitable for the labeling process with the radionuclides. Stable AgNPs is one of the important factors to obtain a stable radiolabeled AgNPs (AgNPs- ${ }^{131} \mathrm{I}$ ). According to a previous study, UVVis spectra recorded for biosynthesized of AgNPs 
were between 350 and $450 \mathrm{~nm}$ as specific SPR of AgNPs [19]. In this research, the results of UV-Vis spectra also indicate an increase of the surface plasmon vibrations at about $390 \mathrm{~nm}$ wavelength.

Transmission electron microscopy data indicates that AgNPs size is below $10 \mathrm{~nm}$ [20] as shown in Fig. 2. The morphological form and size appears to be affected by the experimental conditions, kinetic interactions of metal ions and the nanoparticles (NPs) adsorption with stabilizers [5]. The result of zeta measurement was $-8 \mathrm{mV}$, which is affected by $\mathrm{pH}$, concentration, ionic strength, and temperature [21].

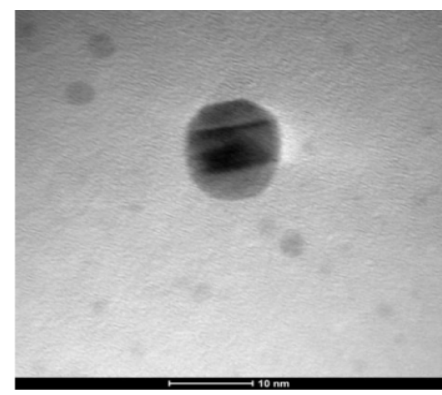

Fig. 2. TEM Image of AgNPs.

The particle size analysis of AgNPs gave a polydispersity index value of 0.455 , which indicates that the AgNPs are quite homogeneous. Nanoparticles is considered completely homogeneous when the index value of polydispersity is close to zero. The actual size of the synthesizedAgNPs based on PSA analysis is shown in Table 1.

Table 1. Particle size distribution based on volume.

\begin{tabular}{cc}
\hline Size d $(\mathrm{nm})$ & Mean Volume (Percent) \\
\hline 0.965 & 0 \\
1.117 & 1.2 \\
1.294 & 4.5 \\
1.499 & 7.4 \\
1.736 & 7.5 \\
2.010 & 5.5 \\
2.328 & 3.9 \\
2.696 & 4.7 \\
3.122 & 7.4 \\
3.615 & 9.9 \\
4.187 & 10.8 \\
4.849 & 10.1 \\
5.615 & 8.4 \\
6.503 & 6.4 \\
7.531 & 4.6 \\
8.721 & 3.0 \\
10.100 & 1.8 \\
11.700 & 1.0 \\
13.540 & 0.5 \\
15.690 & 0.3 \\
\hline
\end{tabular}

The diameter by volume (Dv) of AgNPs, where the value of Dv10, Dv50, and Dv90 are 1.52, $3.79 \mathrm{~nm}$ and $7.65 \mathrm{~nm}$ respectively. It means that 10,50 and $90 \%$ of the total particle has a size below $1.52,3.79$ and $7.65 \mathrm{~nm}$ respectively. This corresponds to the TEM results which show that the AgNPs size is below $10 \mathrm{~nm}$.

\section{Radionuclide purity test of $\mathrm{Na}^{-131}$ I}

Radionuclide purity of $\mathrm{Na}^{-131} \mathrm{I}$ is an important parameter for radiolabelling. Gamma-ray spectrometer analysis shows that the $\mathrm{Na}^{-131} \mathrm{I}$ produced in this research has the energies as listed in Table 2 and Fig. 3. The radionuclide purity is more than $99.9 \%$ (by gamma-ray spectrometer) without other radionuclide impurities. This result complies with the radiopharmaceutical requirement for radionuclidic purity, i.e., $\geq 99.9 \%$ [22].

Table 2. The energy of Iodine-131 $\left({ }^{131} \mathrm{I}\right)$.

\begin{tabular}{cccc}
\hline Isotope & Energy (keV) & $\begin{array}{c}\text { Particle } \\
\text { Emitted }\end{array}$ & $\begin{array}{c}\text { Counts } \\
(\mathrm{cpm})\end{array}$ \\
\hline${ }^{131} \mathrm{I}$ & 248 & $\gamma$ & 1696 \\
& 364 & & 14565 \\
& 636 & & 699 \\
& 721 & & 175 \\
\hline
\end{tabular}

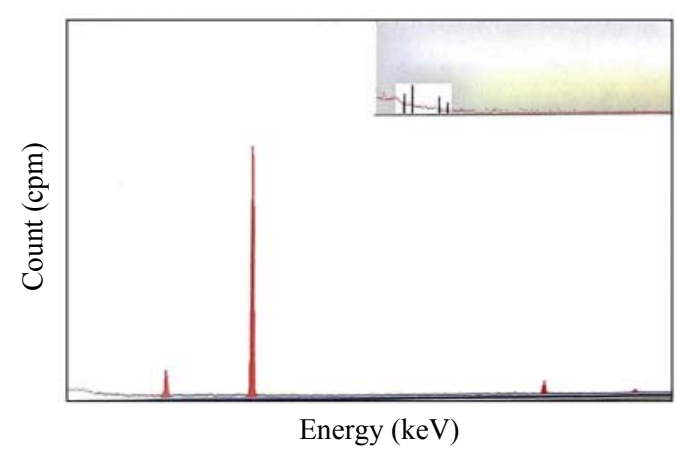

Fig. 3. Analysis result of radionuclide ${ }^{131} \mathrm{I}$ using Gamma Spectrometer.

\section{Radiolabeling of AgNPs with ${ }^{131}$ I}

The labeling of AgNPs was done 3 times with the best labeling results when using a total activity of $11.84 \mathrm{MBq} / \mathrm{mL}$ of the ${ }^{131}$ I solution incubated with immobilized Chloramine-T. In this research, the low activity of ${ }^{131} \mathrm{I}$ ij $\mathrm{s}$ to minimize exposure during the experiment. The resulted AgNPs- ${ }^{131}$ I solution is a clear yellow solution as shown in Fig. 4. The color of AgNPs before and after radiolabeling with ${ }^{131} \mathrm{I}$ was found to be similar. This indicates that AgNPs${ }^{131} \mathrm{I}$ is still stable without any aggregation. The AgNPs- ${ }^{131}$ I radioactivity was measured using a dose calibrator, and the result was $3.57 \mathrm{MBq} / \mathrm{mL}$. 


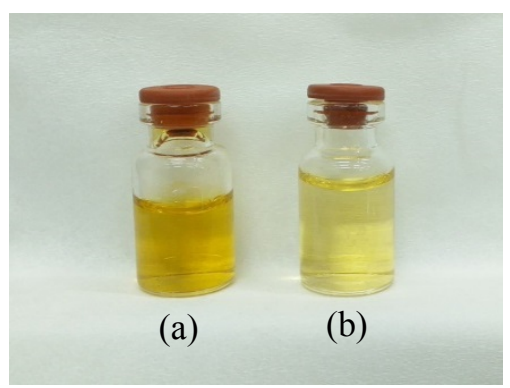

Fig. 4. AgNPs (a) and $\operatorname{AgNPs}^{131} \mathrm{I}$ (b) sample.

\section{Radiochemical purity test of AgNPs- ${ }^{131}$ I}

The radiochemical purity of AgNPss ${ }^{131}$ I was measured by a gamma counter. The iodine-131 bulk and radiolabeling results are presented in Fig. 5 a and $b$. The results of the ${ }^{131}$ I bulk and radiolabeled compound AgNPs ${ }^{131}$ I show different migration. The radionuclide ${ }^{131} \mathrm{I}$ sample has a retention factor $(\mathrm{Rf})=$ 0.6 while the AgNPs ${ }^{131} \mathrm{I}$ has $\mathrm{Rf}=0$. Based on the peak chromatogram in Fig 5.a, the Iodine-131 is indicated as $\mathrm{I}^{-}$form. The radiochemical purity of ${ }^{131} \mathrm{I}$ as the raw material was $98.42 \%$ and the product of AgNPs- ${ }^{131}$ I was $96.49 \%$. These results meet the radiochemical purity standards required by pharmacopeia [23]. The radiochemical purity of ${ }^{131} \mathrm{I}$ and AgNPs $-{ }^{131} \mathrm{I}$ are in accordance with the European Pharmacopoeia 8.0 standard, i.e., the limit of radiochemical purity is no less than $92 \%$ for Iodine131 therapy [24].

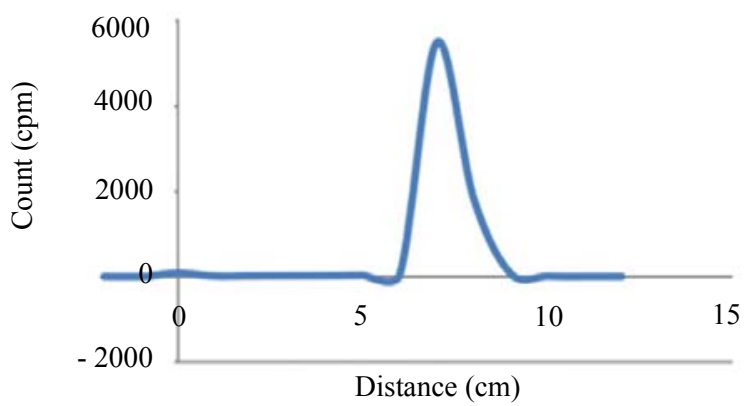

(a)

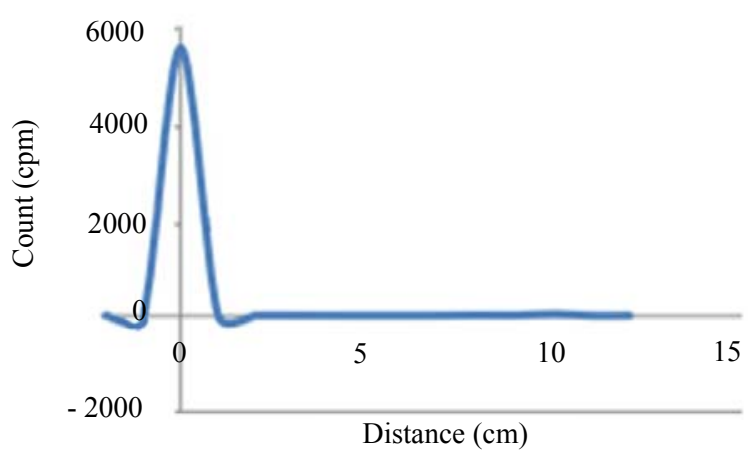

(b)

Fig. 5. Radiochromatogram of ${ }^{131} \mathrm{I}$ (a) and $\mathrm{AgNPs}^{-131} \mathrm{I}$ (b).

\section{CONCLUSION}

The synthesis of AgNPs has been successfully performed by reduction method. The synthesized AgNPs had a spherical shape with diameter below $10 \mathrm{~nm}$ and zeta potential value of $-8 \mathrm{mV}$. The AgNPs was radiolabeled with ${ }^{131} \mathrm{I}$ through chemisorption method, and the resulted AgNPs ${ }^{131} \mathrm{I}$ has radiochemical purity of $96.49 \%$.

\section{ACKNOWLEDGMENT}

The authors would like to thank Dra Siti Darwati, M.Sc and Dra Widyastuti, M.Farm for their support and discussion. Financial support from Ministry of Research Technology and Higher Education, Indonesia is gratefully acknowledged.

\section{REFERENCES}

1. M.E. Crestoni, Radiopharmaceuticals for Diagnosis and Therapy, in: Reference Module in Chemistry, Molecular Sciences and Chemical Engineering, Elsevier, United Kingdom (2018).

2. J. Mukiza, E. Byamukama, J. Sezirahiga et al., Rwanda Medical Journal 75 (2018) 14.

3. S.V. Gudkov, N.Y. Shilyagina, V.A. Vodeneev et al., Int. J. Mol. Sci. 17 (2016) 33.

4. A. Boschi, L. Uccelli and P. Martini, Appl. Sci. 9 (2019) 2526.

5. S. Chaturvedi and A.K. Mishra, Front. Med. 3 (2016) 1.

6. B. Khodashenas and H.R. Ghorbani, Arab. J. Chem. 12 (2019) 1823.

7. L. Farzin, S. Sheibani, M.E. Moassesi et al., J. Biomed. Mater. Res. 107 (2019) 251.

8. G. Bisht and S. Rayamajhi, Nanobiomedicine 3 (2016) 1.

9. A. Chrastina and J. E. Schnitzer, Int. J. Nanomedicine 5 (2010) 653.

10. H. Sadeghpour, M. Alavi, M. Shahedi et al., Trends in Pharmaceutical Sciences 1 (2015) 15.

11. Y. Khan, M. Qasimnasar, M. Numan et al., Int. J. Nanotechnol. Nanomed. 3 (2018) 1.

12. U.N. Sholikhah, A. Pujiyanto, E. Lestari et al., J. Pure App. Chem. Res. 5 (2016) 173.

13. S.E. Permatasari, 131I-Radiolabelled Silver Nanoparticle for Radiotheraphy, Undergraduate Thesis, University of Indonesia (2017). (in Indonesian). 
14. S.V. Bannea, M.S. Patil, R.M. Kulkarnic et al., Materials Today: Proceedings 4 (2017) 12054.

15. C. Yen, H. Puigc, J.O. Tama et al., Lab. Chip. 15 (2015) 1638.

16. V. Sharma, D. Verma, and G.S. Okram, J. Phys.: Condens. Matter 32 (2020) 145302.

17. A.D. Kondorskiy, N.T. Lam and V.S. Lebedev, J. Russ. Laser Res. 39 (2018) 56.

18. S.S. Hinman, K.S. McKeating and Q. Cheng, Anal. Chem. 90 (2019) S1.
19. P. Roy, B. Das, A. Mohanty et al., Appl. Nanosci. 7 (2017) 843.

20. M. Negahdary, S. Omidi, A. Eghbali-Zarch et al., Biomedical Research 26 (2015) 794.

21. B. Neacsu, C. Cimpeanu and C. Barna, Romanian Reports in Physics 65 (2013) 155.

22. M. Klučáková, Front. Chem. 6 (2018) 1.

23. Anonymous, USP35 NF30: U.S. Pharmacopeia National Formulary, United States Pharmacopeia (2012).

24. Anonymous, European Pharmacopoeia, 8th Ed. Vol. 1, Council Europe (2013). 